\title{
Structural condition assessment of a reinforced concrete driveway
}

\author{
Piotr Berkowski ${ }^{1, *}$, Grzegorz Dmochowski² \\ ${ }^{1}$ Wroclaw University of Science and Technology, Faculty of Civil Engineering, Wyspiańskiego Blvd., 27, Wroclaw, Poland \\ ${ }^{2}$ Wroclaw University of Science and Technology, Faculty of Civil Engineering, Wyspiańskiego Blvd., 27, Wroclaw, Poland
}

\begin{abstract}
The reinforced concrete structure of a driveway built in the eighties of the $20^{\text {th }}$ century is under consideration. It is a single-storey structure with a length of approx. $66.00 \mathrm{~m}$, made in the form of a reinforced concrete skeletal structure, consisting of 7 frames with cantilevers, spaced at $9.00 \mathrm{~m}: 3$ frames in the horizontal part of the driveway are three-span ones, and 4 in the sloping part are single-span frames. The driveway frame main beams have a rectangular cross-section and are based on pillars that have been placed on the spread footing - these elements form a monolithic structure. Prefabricated reinforced concrete hollow floor plates were laid on them in the central part of the driveway, and in the outer parts the driveway floor was made of hollow clay slab blocks (Ackerman type). At the time of investigation, the upper layers of the driveway consisted of a surface waterproofing layer, a concrete slab of approx. $10 \mathrm{~cm}$ thickness made on a $1 \mathrm{~cm}$ sand layer. However, no internal waterproofing layer was found as was in the original design. The paper describes the process of determining the current technical condition of the reinforced concrete driveway structure, paying attention to the design and construction of the object, its operation (including the issues of durability of concrete under the conditions of possible impacts of the marine environment). Static and strength calculations were also performed (supported by concrete and reinforcement tests) and the conditions for further operation of the driveway were analyzed as well as concepts of rehabilitation.
\end{abstract}

\section{Description of the driveway structure}

The reinforced concrete structure of a driveway was built in the early eighties of the $20^{\text {th }}$ century in the immediate vicinity of the sea coast. Its structural layout results from the terrain on which it is located, and it is functionally used as an access ramp to the level of the third floor of the adjacent building (Fig. 1).

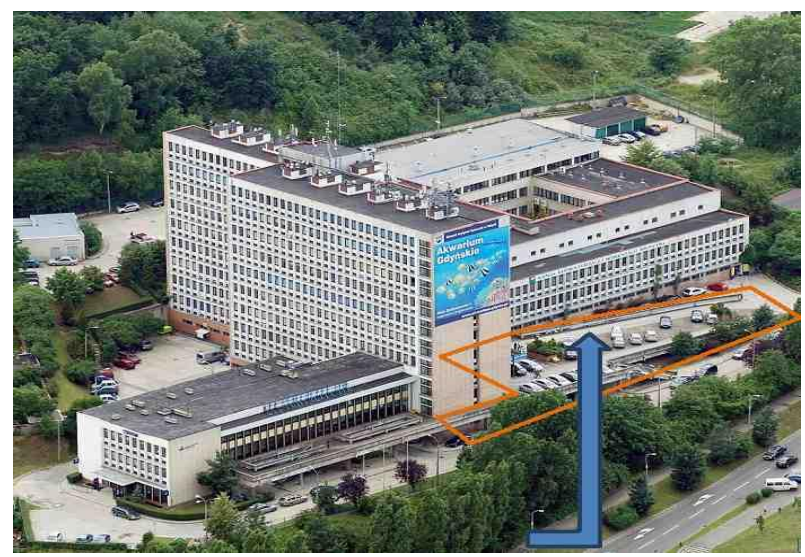

Fig. 1. Location of the driveway.

The driveway, in addition to the access function, is used as a parking place for private cars. Besides, parking spaces are also located under its horizontal part.
From the structural point of view the driveway is a single-storey structure made in the form of a reinforced concrete skeletal structure, and consists of 7 frames (Fig. 2) with cantilevers: 3 frames in the horizontal part of the driveway are three-span ones, and 4, in the sloping part, are a single-span ones. At the level of the upper girders, frames are monolithically connected by main beams, situated along the length of the driveway.

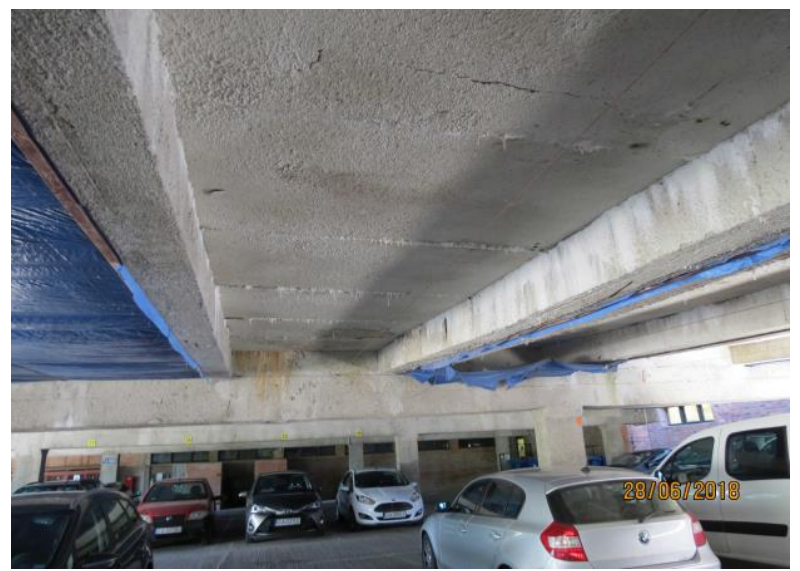

Fig. 2. Bearing frames and main beams of the driveway.

The slab of the structure is made of prefabricated, hollow plates in the central part of the driveway, and in its outer

* Corresponding author: piotr.berkowski@pwr.edu.pl 


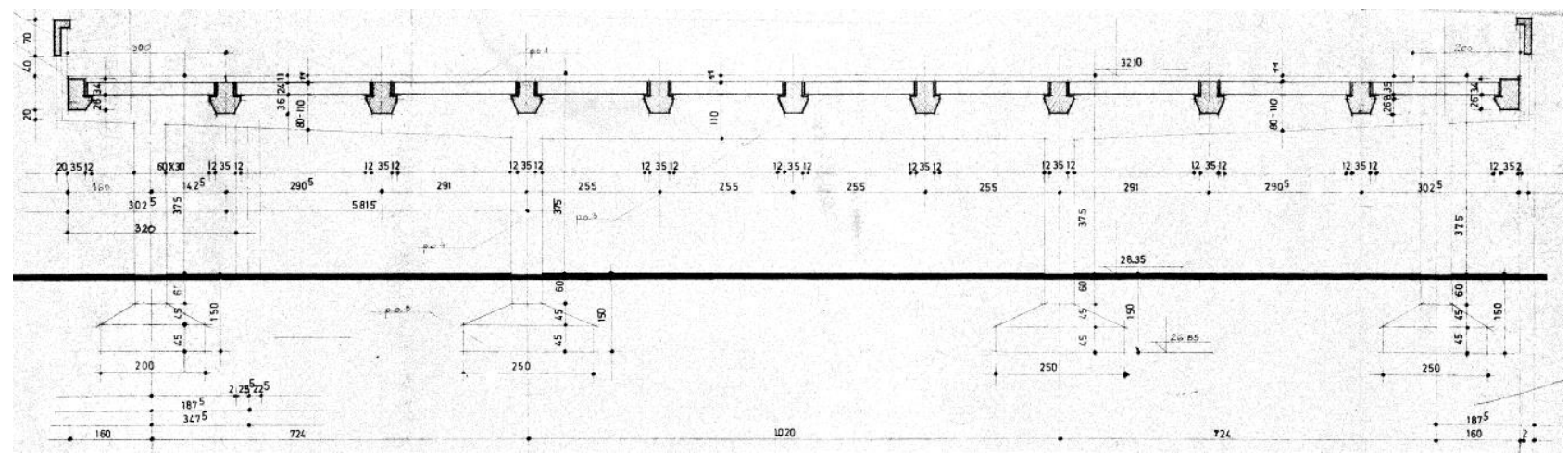

Fig. 3. Cross-section of the driveway bearing structure [2].

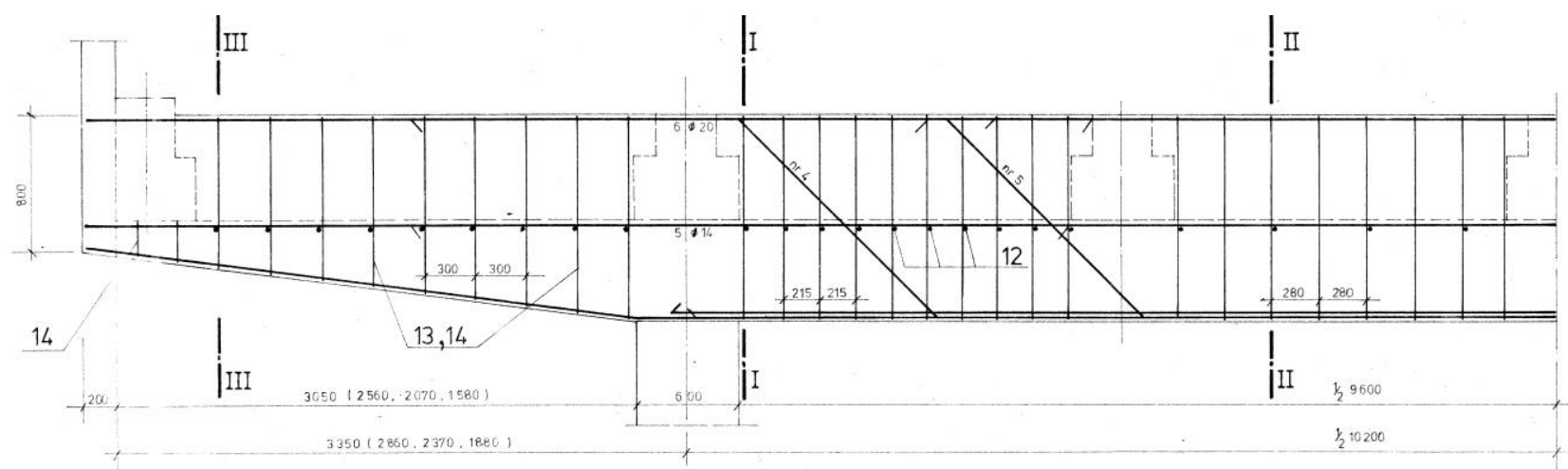

Fig. 4. Reinforcement of the transverse frame [3].

parts the plate is constructed in the form of the ribbed floor slab made of the Ackerman hollow clay blocks [1]. The pavement of the driveway is made in the form of a concrete slab.

\subsection{Analysis of the existing old technical documentation}

The original design documentation from 1973 consists of two parts: architectural design [2] and constructional one [3].

The first of them contains a technical description and architectural drawings of the driveway with all functional, geometrical and material data. In this design the platform and passage were designed as a monolithic reinforced concrete structure with transverse frames and longitudinal ribs (Fig. 3). The platform deck was designed from prefabricated hollow plates, and its trapezoidal parts - from Ackerman blocks. The surface of the pedestrian part was designed from flagstones and the driveway with an asphalt pavement.

The second part of the documentation consists of technical description, structural calculations and constructional drawings (Fig. 4) of the platform and driveway based on the architectural design. The driveway was calculated for a service load of $5 \mathrm{kN} / \mathrm{m}^{2}$ or from a vehicle of $20 \mathrm{kN}$. The concrete strength of $\mathrm{R}_{\mathrm{w}}=$ $200 \mathrm{~kg} / \mathrm{cm}^{2}$ (20 MPa) for prefabricated elements and $R_{W}$ $=170 \mathrm{~kg} / \mathrm{cm}^{2}(17 \mathrm{MPa})$ for in-situ elements were assumed. Ribbed reinforcement steel with a $\mathrm{Q}_{\mathrm{r}}=4.200$ $\mathrm{kg} / \mathrm{cm}^{2}(420 \mathrm{MPa})$ and a smooth reinforcement with $\mathrm{Q}_{\mathrm{r}}=$ $2.500 \mathrm{~kg} / \mathrm{cm}^{2}(250 \mathrm{MPa})$ were adopted.

The following structural models were applied in the static calculations:

$>$ for Ackerman floor - a single-span beam, freely supported;

$>$ for longitudinal beams - 4- or 5-span continuous beams;

$>$ for transverse frames - for girder of a 1-span frame: a single-span beam with cantilevers; for girder of a 3span frame: a 3-span continuous beam with cantilevers;

$>$ for transverse frames columns - axially compressed columns;

$>$ for foundations - axially loaded footings.

A material assessment regarding the quality of concrete in the construction of the driveway was conducted in 2005 [4]. The documentation contains results of concrete tensile strength tests (adhesion) using the "pull-off" method, chemical analysis for $\mathrm{SO}_{4}{ }^{2-}$ and $\mathrm{Cl}^{-}$ion content as well as determination of the $\mathrm{pH}$ value. The results were as follows:

tensile strength of concrete ranging from 0.51 to 1.78 $\mathrm{MPa}$ in monolithic elements that proved the diversity of concrete made at the construction site; for a prefabricated slab, the tensile strength of concrete was $2.56 \mathrm{MPa}$ which proved the better quality of concrete in the prefabricated panels; 
the content of $\mathrm{SO}_{4}{ }^{2-}$ ions (sulfates) was determined from 0.021 to $0.112 \%$, which is the quantity normally found in concrete;

$>$ the content of $\mathrm{Cl}^{-}$ions in the concrete of the bottom parts of the structure, despite pillars, was at the level that did not cause corrosion of reinforcement and concrete; the $\mathrm{pH}$ value in all samples tested, except for the columns, was greater than the limit value of $11.4 \mathrm{pH}$ (or $12.0 \mathrm{pH}$ for the occurrence of $\mathrm{Cl}^{-}$ions); only in one of the pillars was the $\mathrm{pH}$ value a little lower than the limit that could start the corrosion process.

\subsection{Current structural system of the driveway}

The driveway consists of 3 main functional elements: a slanted part with a slope of approx. $6^{\circ}$ and a trapezoidal plan of approx. 13.0-18.0 per $45.0 \mathrm{~m}$, a horizontal parking platform with dimensions of approx. 21.0-28.0 $\mathrm{m}$ and the remnants of the pedestrian communication platform (terrace). The total length of the construction of the driveway is approx. $66.0 \mathrm{~m}$ (Fig. 5).

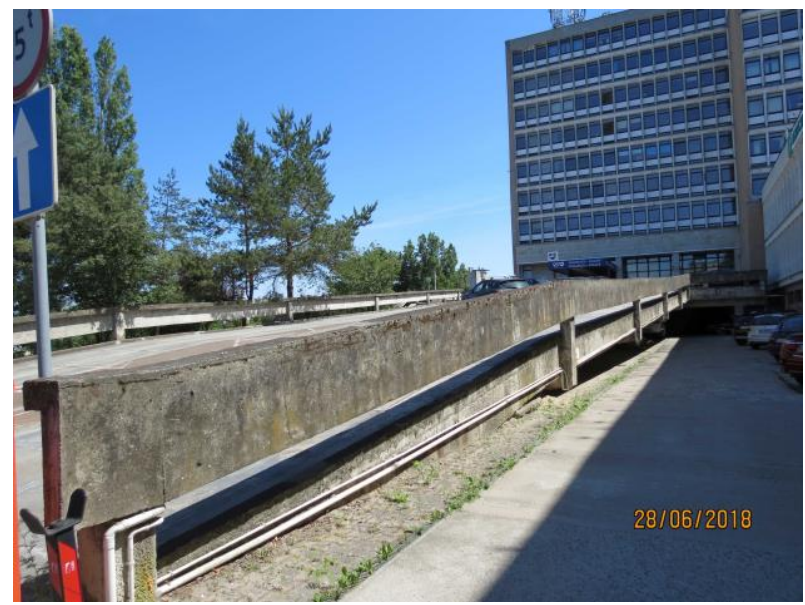

Fig. 5. General view of the driveway in 2018 .

The supporting structure of the driveway is a system of 7 monolithic reinforced concrete frames with cantilevers: 4 frames are single-span and 3 are three-span ones. The length of the central span is approx. $10.20 \mathrm{~m}$ and of the extreme spans - approx. $7.24 \mathrm{~m}$. The cantilevers have variable outreaches of 2.08, 2.57, 3.06 and $3.55 \mathrm{~m}$. The frame girders have a cross-section of $60 \times 120 \mathrm{~cm}$ and at the end of the cantilever part $-38 \times 60 \mathrm{~cm}$. The main columns of the frames have a cross-section of $40 \times 60 \mathrm{~cm}$ with 10 bars of $14 \mathrm{~mm}$ diameter, while the end columns of two-span frames and a pedestrian bridge $-30 \times 60 \mathrm{~cm}$ with 12 bars of $14 \mathrm{~mm}$ diameter. The frame girders are bases for longitudinal ribs in the shape of an inverted Tletter sections with dimensions $60 \times 60 \mathrm{~cm}$, spacing 2.55 to $2.90 \mathrm{~m}$, and on the cantilevers - side ribs with a crosssection of $35 \times 60 \mathrm{~cm}$, running along the driveway. The side rib along the pedestrian bridge has a width changing from 47 to $35 \mathrm{~cm}$ and a height of $60 \mathrm{~cm}$. The transverse frame system (transoms with brackets and posts) and longitudinal ribs form a monolithic system.

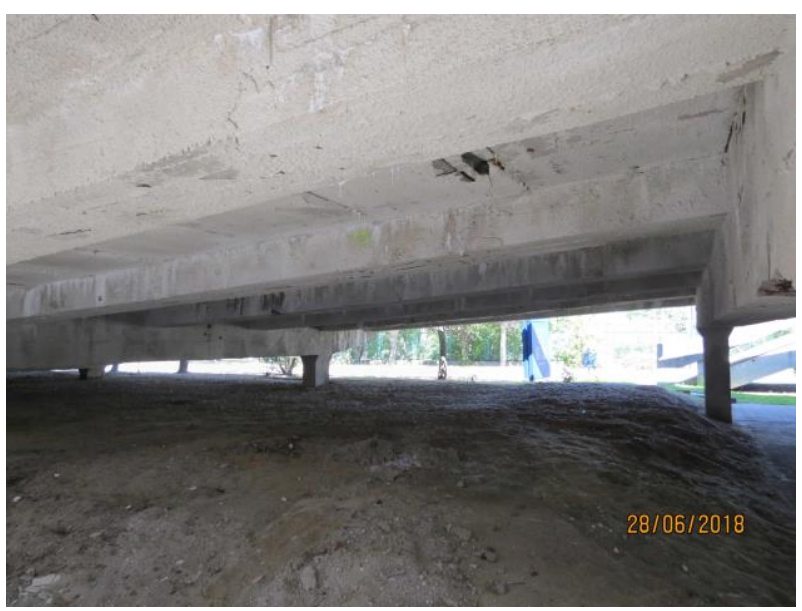

Fig. 6. View of the driveway main bearing structure.

On the shelves of the ribs, prefabricated hollow plates with a thickness of $24 \mathrm{~cm}$, width $120 \mathrm{~cm}$ and length 217 $\mathrm{cm}$ (reinforced with $10 \mathrm{~mm}$ bars) are mounted, and in the trapezoidal end areas a ceiling is made of Ackerman airbricks (reinforced in ribs with $18 \mathrm{~mm}$ bars) with a 4 cm concrete upper layer (Fig. 7).

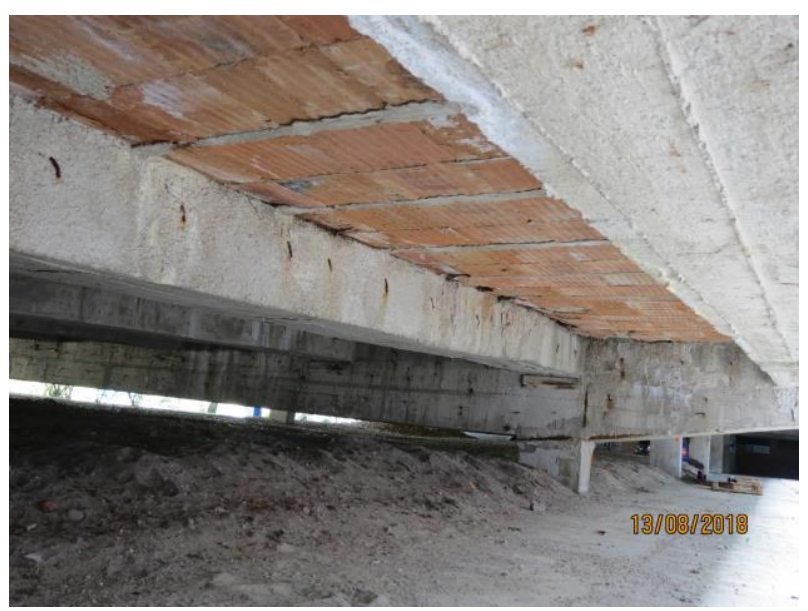

Fig. 7. View of the Ackerman slab.

The foundation of the columns was designed as the footing 250x250 cm with slants and height $90 \mathrm{~cm}$, on lean concrete. Foundations were placed $1.50 \mathrm{~m}$ below ground level.

The driveway is equipped with reinforced concrete balustrades with a height of $1.10 \mathrm{~m}$, consisting of posts $25 \times 30 \mathrm{~cm}$, mounted at the ends of cross-frame brackets, and topped with inverted L beams, $70 \mathrm{~cm}$ high and 15 cm thick (Fig. 8).

The following layers of driveway floor were found on the basis of the core drillings made in the places where the prefabricated hollow plates constitute the slab - from the top of the slab (Fig. 9):

$>$ coating of waterproofing material on the leveling layer $-1.0-1.5 \mathrm{~cm}$;

$>$ main concrete layer $-10 \mathrm{~cm}$;

$>$ sand and cement bedding $-1 \mathrm{~cm}$;

$>$ prefabricated hollow slab $-24 \mathrm{~cm}$;

$>$ plasterboard $-0.5 \mathrm{~cm}$. 


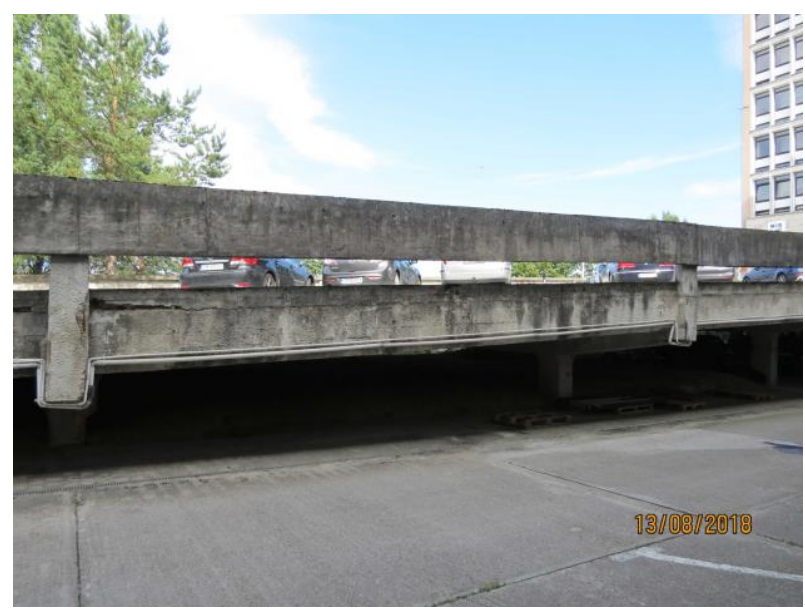

Fig. 8. Driveway concrete balustrades.

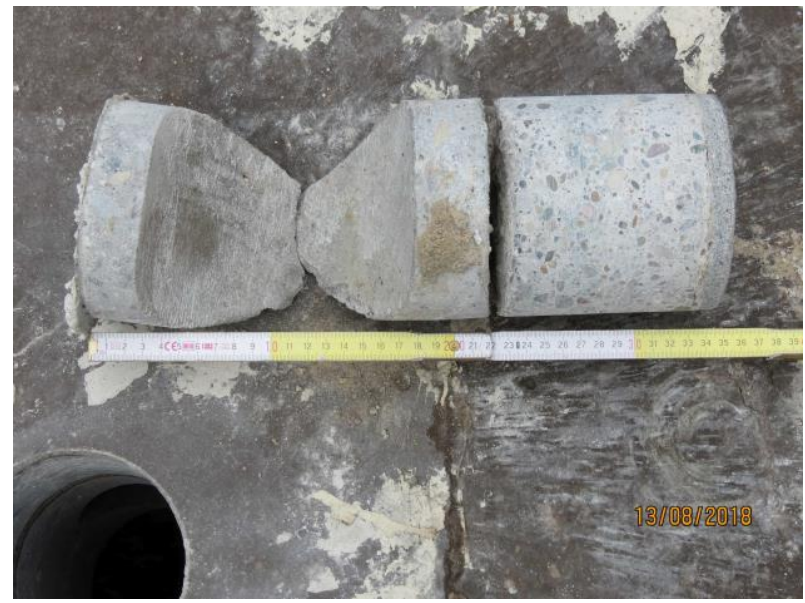

Fig. 9. Core drilling through the driveway slab.

In the outer, trapezoidal, bays instead of prefabricated hollow plates an Ackerman hollow clay blocks ceiling was used with $20 \mathrm{~cm}$ thickness and an upper concrete layer of $4 \mathrm{~cm}$ thickness.

At the time of conducting the assessment, the upper pavement layer at the whole surface of the driveway was protected with different kinds of waterproofing materials as the owner tried to found out the best solution to prevent the continuous leakage of rainwater and melted snow in order to stop concrete destruction (Fig. 10).

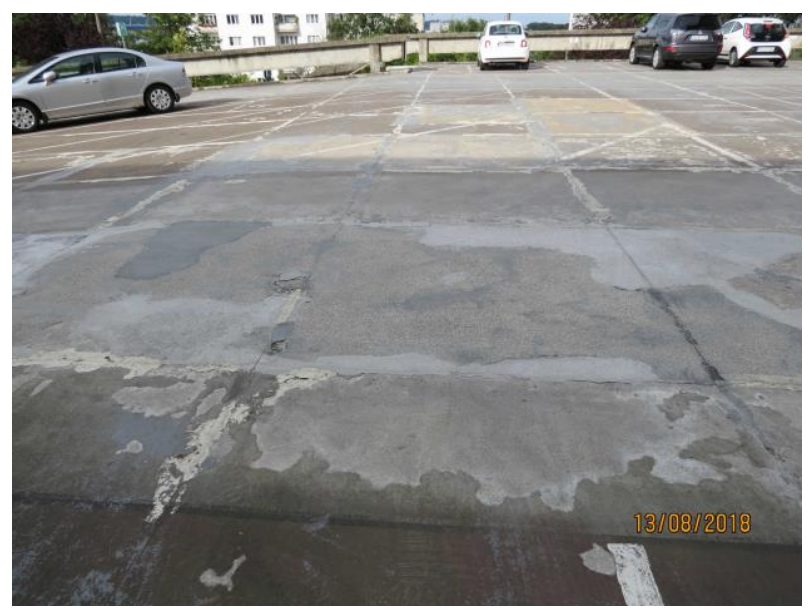

Fig. 10. Different protection layers on driveway surface.

\section{Assessment of the actual driveway technical condition}

A lot of problems connected with leakage of rainwater and melted snow (with de-icing salts) $[5,6]$ through the platform slab occurred during the previous exploitation of the driveway. At the same time, several technical assessments were prepared and the main causes of the degradation of the driveway structural elements were defined as well as solutions of repair or protection proposed.

As the life of the driveway structure was close to the serviceability limit, a decision about comprehensive technical assessment [7, 8] and development of the repair concept was taken by the owner. Below, elements of the conducted evaluation process are described.

\subsection{Description of driveway damage}

The following characteristic types of damage of structural and finishing elements [9] were found:

1. Spalling on the surfaces of reinforced concrete elements (Fig. 11).

2. Local surface destruction and material losses due tocorrosion of bars and reinforcement due to insufficient thickness of concrete cover, especially for stirrups (Fig. 11).

3. Local corrosion damage (defects in material) of the exposed main reinforcement bars connected with the exposure of the reinforcement cover (Fig 12).

4. Local losses of the material of the Ackerman blocks (dropping of the lower parts of blocks) and corrosion damage (destruction and loss) of the exposed reinforcement (delamination and cracking of the ceramic as a result of freezing water penetrating the leaky surface) (Fig. 13).

5. Local damage of hollow-core slabs (dropping of lower plate fragments) and corrosion damage of exposed reinforcement (delamination and loosening of concrete lagging as a result of freezing water penetrating through the leaky surface) (Fig. 14).

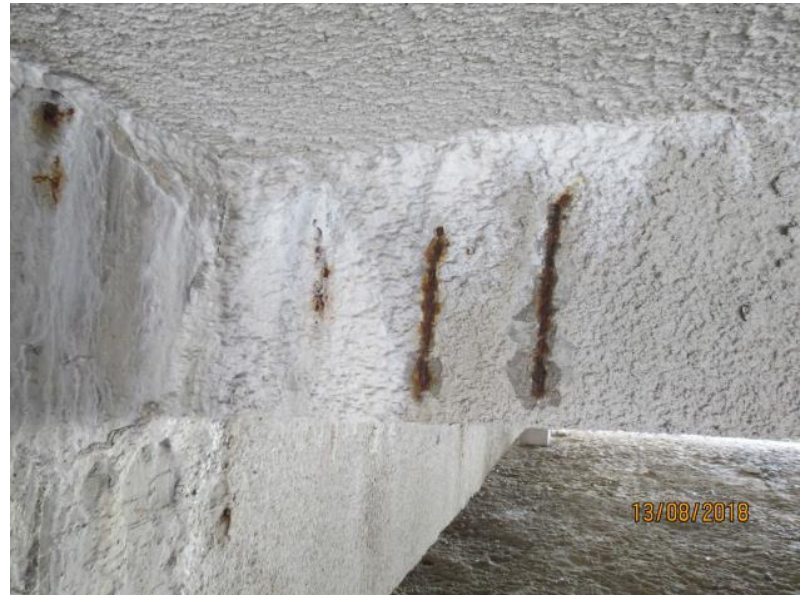

Fig. 11. Spalling and lack of proper rebar cover. 


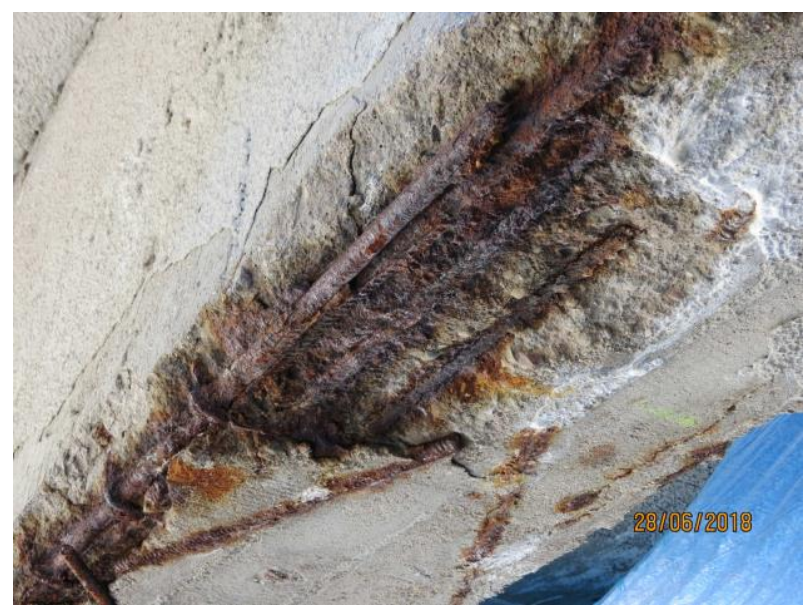

Fig. 12. Reinforcement corrosion.

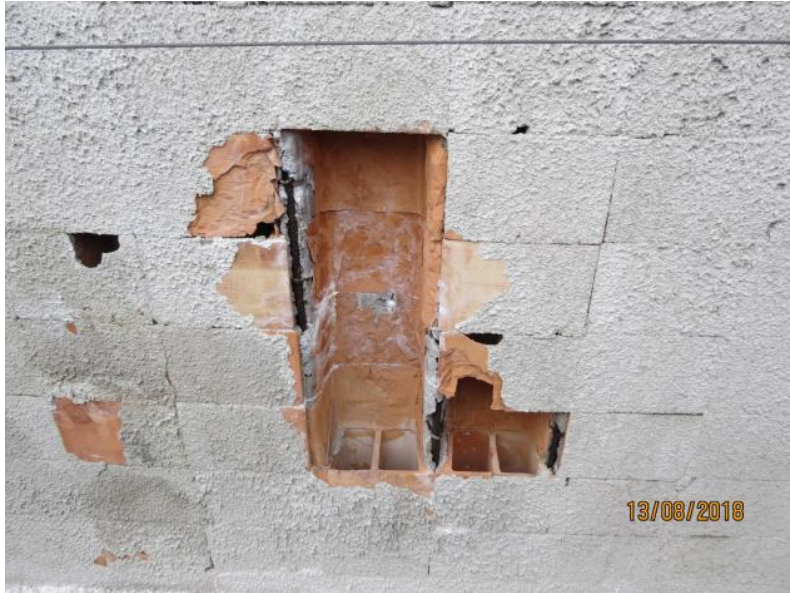

Fig. 13. Destruction of Ackerman hollow clay blocks slab.

6. Local cavities and delamination of concrete, corrosive damage (destruction and defects of material) of reinforcement bars in balustrades.

7. Delamination (de-bonding) at the edge contact of the end ribs and the curb of the driveway plate.

8. Organic contamination (overgrowing with mosses), resulting in the destruction of plaster and surface concrete (Fig. 15).

9. Freeze-thaw destruction of the driveway surface and material losses and delamination of the pavement surface (Fig. 16).

10. Prolonged leaching of concrete material components as a result of water penetration - water stains and stalactites on the lower surfaces of plates as well on frames and ribs surfaces (Fig. 17).

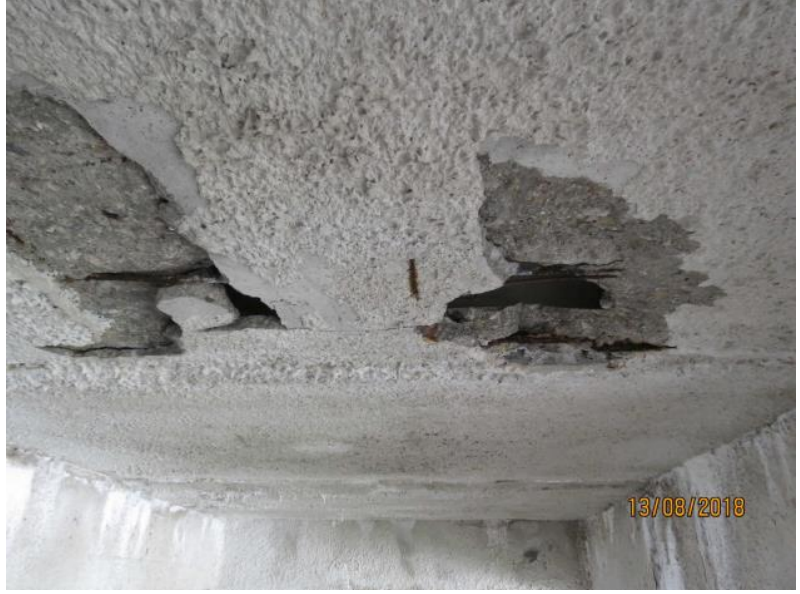

Fig. 14. Destruction of prefabricated hollow slabs.

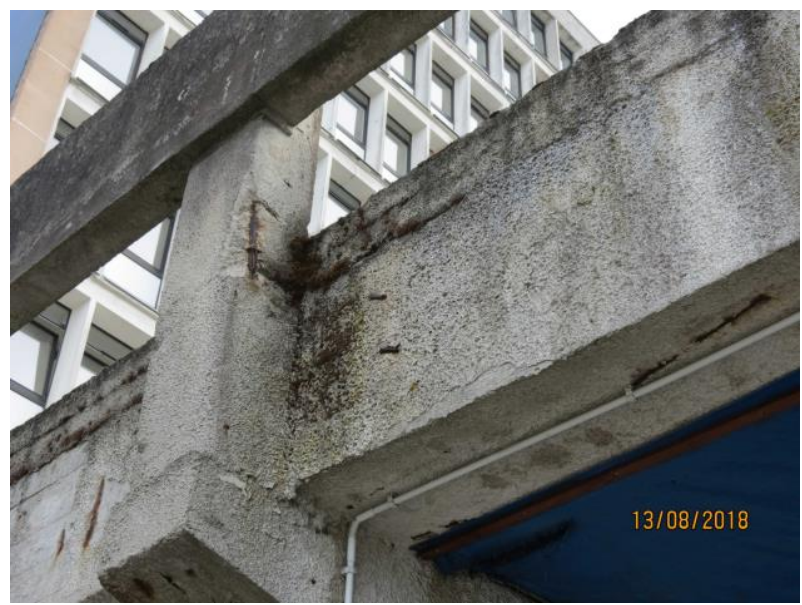

Fig. 15. Destruction due to organic contamination.

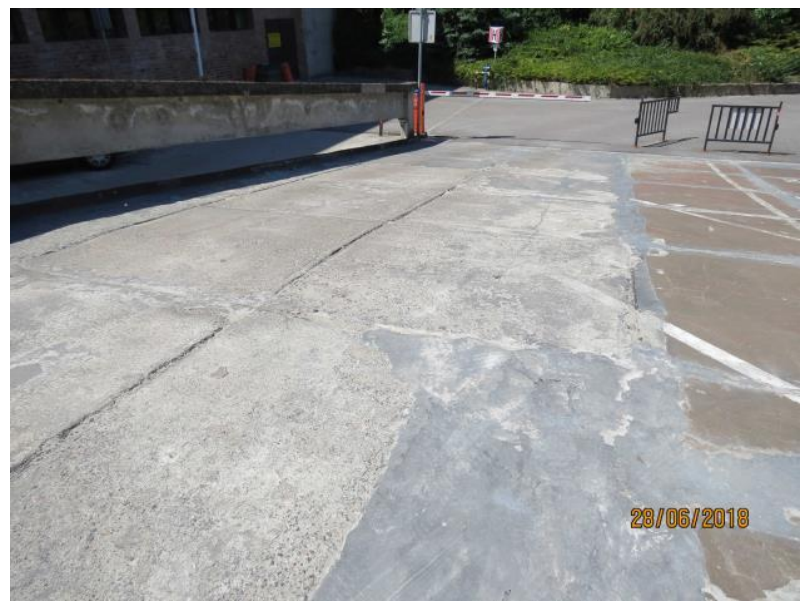

Fig. 16. Destruction of driveway pavement surface. 


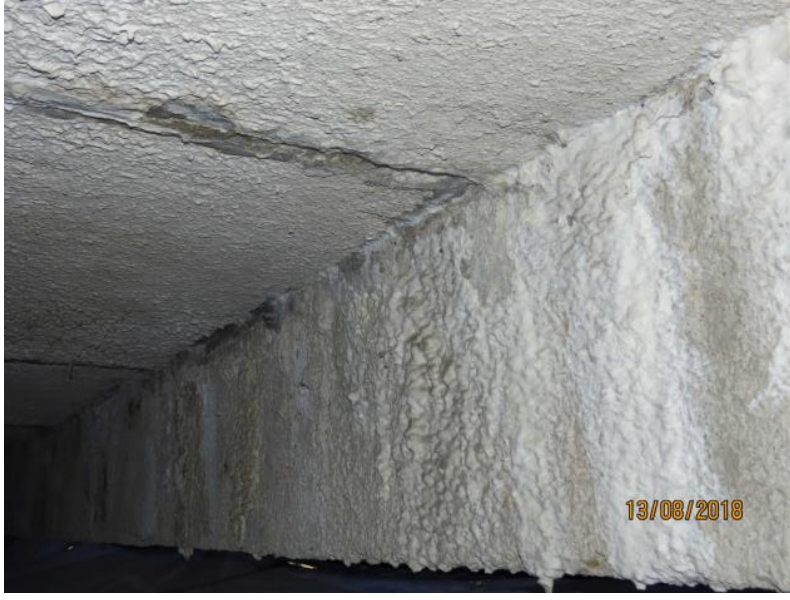

Fig. 17. Salt infiltrations on the surface of structural elements.

\subsection{Description of measurements and tests carried out}

In the procedure of assessing the technical condition of the driveway [7, 8, 9] the following material and structural examinations were made:

$>$ reinforcement openings in different elements of the driveway structure;

$>$ testing of concrete strength with Schmidt hammer;

$>$ an open-pit of the foundation footing of the transverse frame column.

In order to verify the structural reinforcement, its identification was carried out at 16 points: in 5 new pits and in 11 places with damaged concrete cover where the reinforcement was exposed. A PMD10 Bosch metal detector was used to determine the reinforcement situation and a YATO YT-7201 electronic caliper was used to measure reinforcement diameters. Generally, in all the examination points, the reinforcement was as designed. Moreover, in new reinforcement openings no corrosion of the reinforcement was revealed (Fig. 18). However, in previously made openings and in the places where the reinforcement was exposed due to damage of concrete cover, corrosion of the reinforcement was found, with varying intensity (Fig. 19).

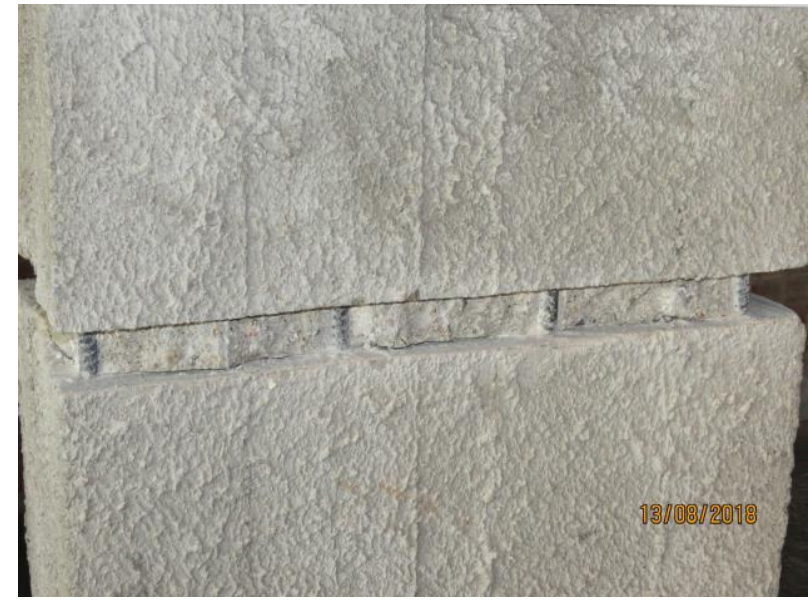

Fig. 18. Reinforcement checking opening in column.

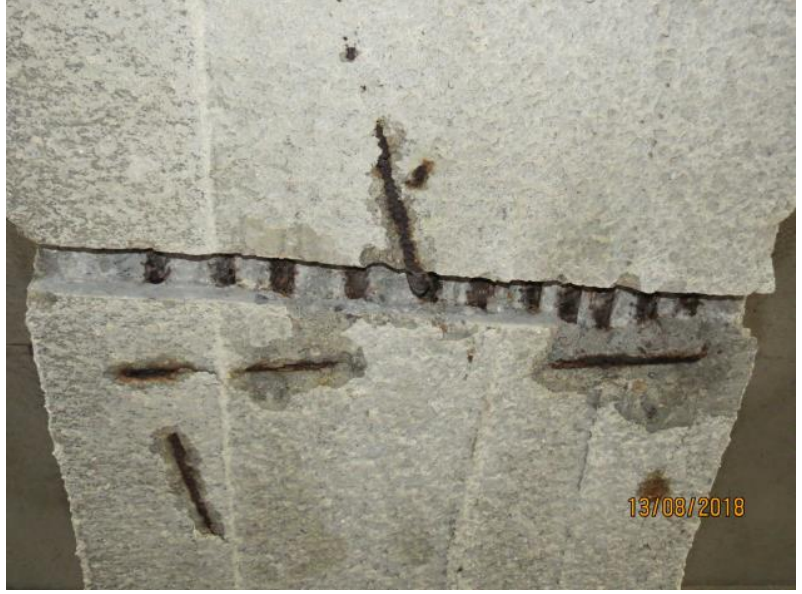

Fig. 19. Reinforcement checking opening in frame girder.

A Proceq Schmidt type N-34 hammer was used to verify the strength of the concrete. On the basis of performed control tests, the following values of concrete strength were calculated statistically:

$>$ in one-span frame girder - B20 (C16/20);

$>$ in three-span frame girder - B15 (C12/15)

$>$ in frame column - B15 (C12/15);

$>$ in main beam - B17,5 (C12/15-C16/20);

$>$ in side beam - B17,5 (C12/15-C16/20)

Concrete with $\mathrm{R}_{\mathrm{w}}=170 \mathrm{~kg} / \mathrm{cm}^{2}$ (17 MPa), according to the standards in force in 1973, was assumed in the original design [2].

In order to verify the geometry of the foundations of the main columns of the supporting frames, a trench was made (Fig. 20). Measurements showed that the foundation had different dimensions than those assumed in the project [3]. In view of the above, the dimensions from the inventory were used to calculate the bearing capacity of the foundations.

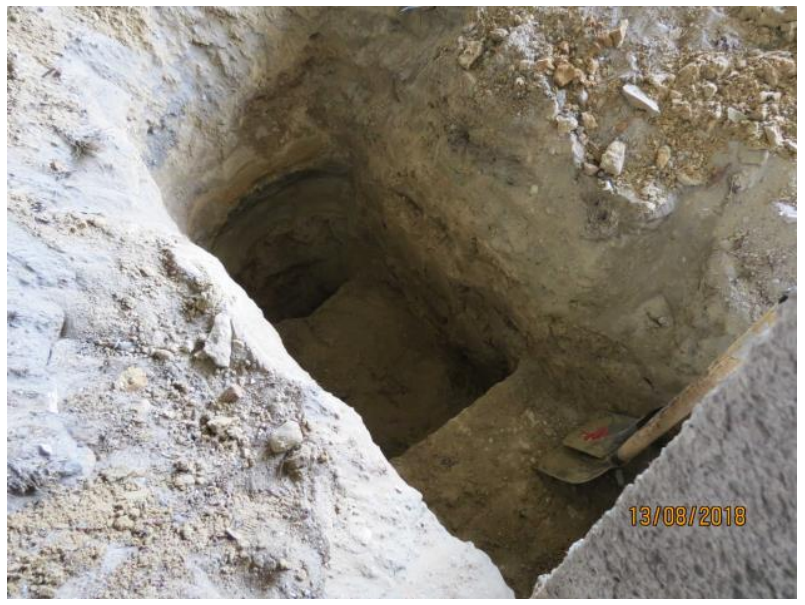

Fig. 20. Foundation inventory.

\subsection{Control static calculations}

Analyses of calculation assumptions adopted for the original design [2,3] were made in order to stay coherent with them during verification of the structural 
capacity for current loads, considering its technical state as well as for predicted rehabilitation solutions.

Based on the results of the conducted strength tests, class B17,5 concrete was adopted for static calculations.

For the control static and strength calculations, the number and layout of the reinforcement bars were taken according to the documentation after verification on the basis of the actual measurements made. The strength of the reinforcement was assumed as for A-III class.

Due to the simple structural layout of the driveway structure and the lack of linking of the driveway slab with ribs and frame girders, a bar model was adopted for the calculation, reflecting the arrangement of existing ribs and transverse frames. Analogous static schemes were assumed by the authors of the driveway project [3].

The following structural elements were checked both for the current state and loads and for predicted rehabilitation designs and loads, including temperature:

bearing capacity of prefabricated hollow slabs;

$>$ bearing capacity of longitudinal ribs;

$>$ bearing capacity of single-span lateral frames (girders, cantilevers, columns);

$>$ bearing capacity of three-span lateral frames (girders, cantilevers, columns);

$>$ bearing capacity of foundations.

\subsection{Some remarks on the driveway technical state}

Conclusions from the analysis of the design documentation and identification of structure:

1. The most important constructional error was the lack of a waterproofing layer that was recommended in the project $[2,3]$.

2. The design error was not taking into account the environmental conditions influencing the structural material and lack of adoption of sufficient thickness of reinforcement cover.

3. Another design error was lack of execution of an effective rainwater drainage system from the driveway surface.

4. The last design and execution error was also the lack of a proper system of expansion joints.

5. The occurrence of damage to the construction and finishing elements of the driveway results from the coupling of internal factors (design and execution errors) and external (environmental influences) that have resulted in a reduction of the durability of the structure.

6. The direct external cause of damage was the destructive environmental impact on concrete and reinforcement of the structure, in the form of a combined effect: water (rain, snow melts), salts used for defrosting during the winter and temperature changes (especially freezing and thawing cycles, mainly in relation to the cover zone of elements directly exposed to atmospheric and maritime region influences).

7. The direct execution cause of damage of the driveway structure was not constructing it in accordance with the design, i.e. the lack of any waterproofing layer in the driveway surface. Another factor contributing to the destruction process was the destruction of the surface pavement, also made contrary to the original design. The combination of these two elements enabled easy and continuous penetration of water through the driveway slab, longterm destruction of the concrete, and, consequently, local strong corrosion damage of concrete and reinforcement. However, it should be emphasized that only in a few places was damage of this type so significant that in the future, in the absence of repair interventions, there may be a risk of loss of loadbearing capacity of these construction elements.

8. The protecting layers made on the surface of the driveway only partially protect the structural elements from further degradation. However, no damage was found in the driveway structure, such as cracks, deformations, which could result from improper work of the foundations (e.g. settlement, rotation, slippage).

\section{Driveway rehabilitation concepts}

The owner of the driveway was presented with 4 possible rehabilitation concepts depending on the estimated life cycle cost [10] and on the amount of costs necessary to pay. The following rehabilitation ideas were considered:

I. Demolition of the existing structure and constructing a new one with the designed durability of the new structure for 60-80 years

II. Demolition of the concrete pavement and the entire slab of the driveway, as well as stairs and balustrades, and leaving only the transverse supporting frames and longitudinal beams (ribs). Then, execution of a new platform slab, in a composite version or without an assembly with the remaining elements of reinforced concrete structure, with effective waterproofing - surface, expansion, drainage system, balustrades and stairs, followed by material reconstruction and surface protection of reinforced concrete elements left behind - life service expectancy of the structure 30-40 years (Fig. 21).

III. Demolition of the concrete pavement and the slab made of the Ackerman hollow clay blocks, as well as stairs and balustrades, and leaving the transverse support frames, longitudinal beams (ribs) and floor slab made of prefabricated hollow plates. Then, execution of a new, reinforced concrete top slab, 


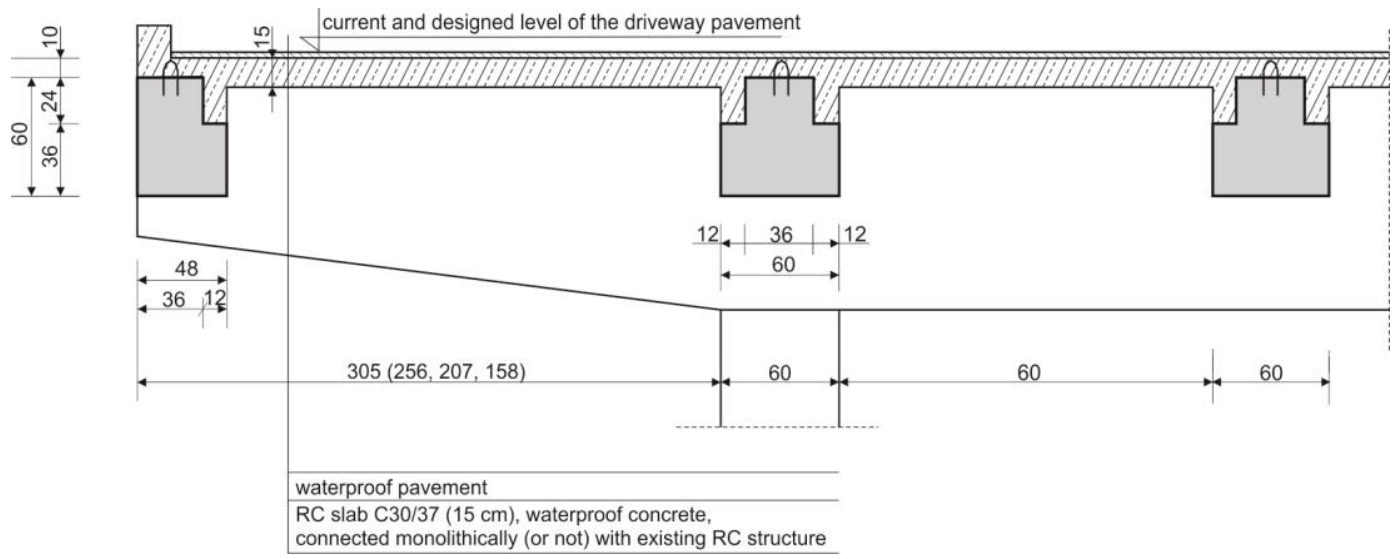

Fig. 21. Driveway renovation concept no. II.

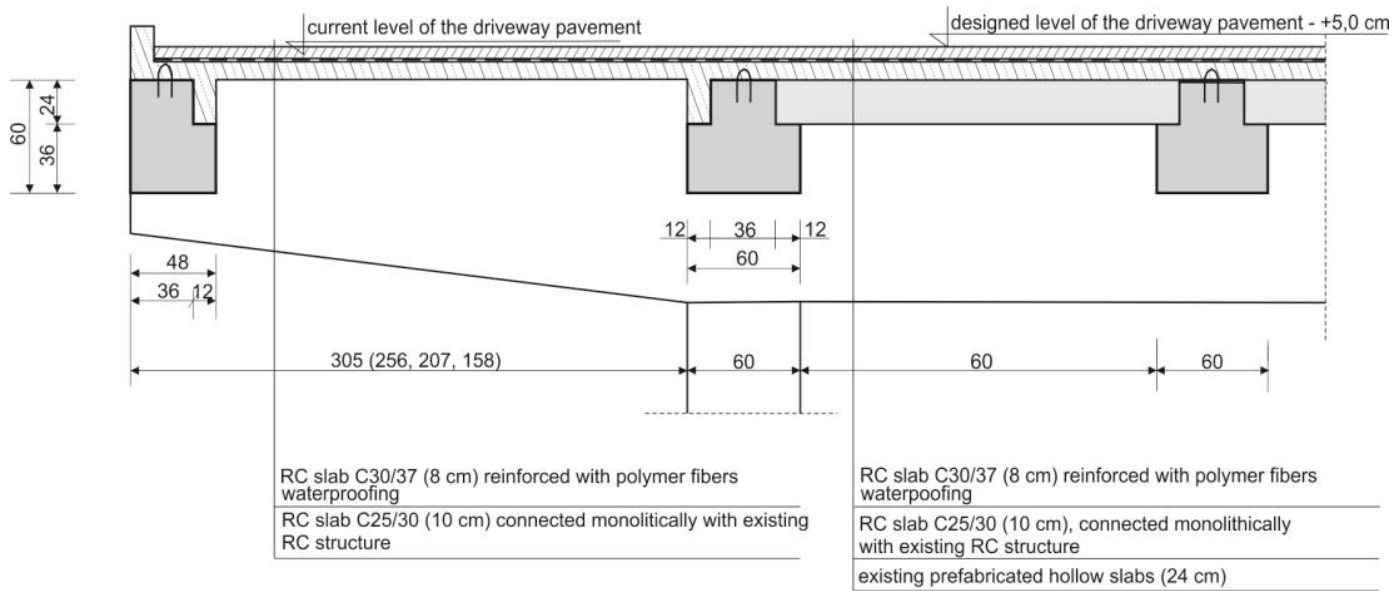

Fig. 22. Driveway renovation concept no. III.

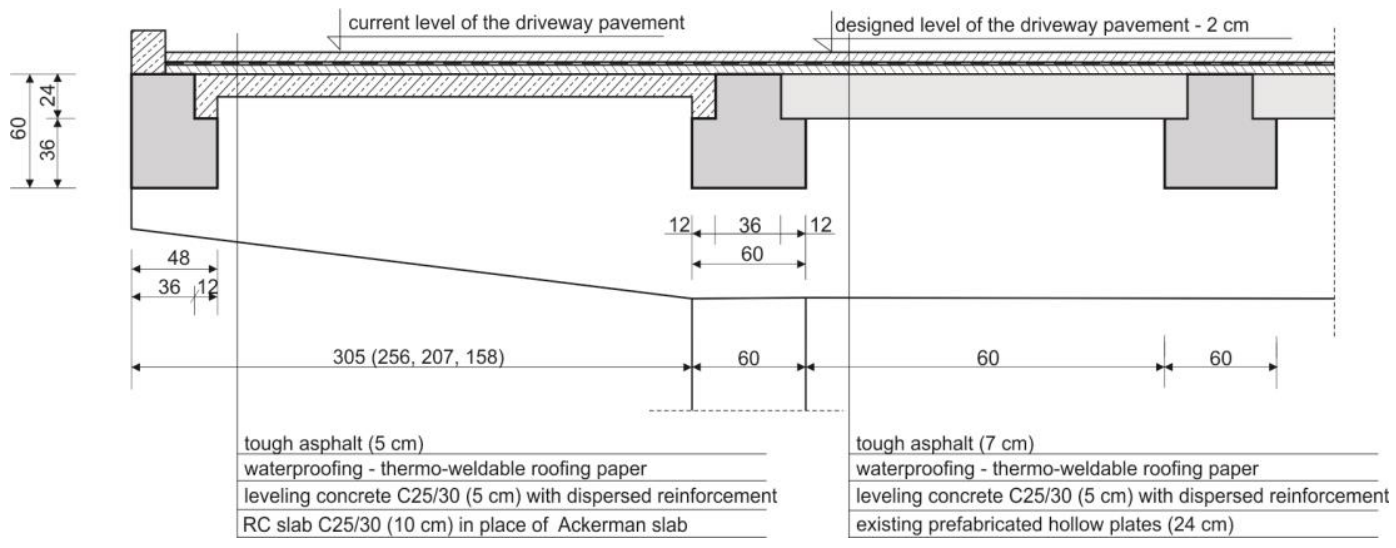

Fig. 23. Driveway renovation concept no. IV.

combined with the remaining construction elements, with a concrete surface reinforced with polymer fibers, effective waterproofing, drainage system, expansion joints, balustrades and stairs; material reconstruction and surface protection of reinforced concrete elements left behind - life expectancy of 1520 years (Fig. 22).
IV.Demolition of the concrete pavement, as well as stairs and balustrades and a slab of hollow clay Ackerman blocks and replacing it with a reinforced concrete slab; leaving transverse supporting frames, longitudinal girders (ribs) and floor slabs of prefabricated hollow RC plates. Then, execution of an additional concrete leveling layer on the entire ceiling, with effective waterproofing; making a new surface made of solid asphalt, with a drainage 
system, proper expansion joint system, new balustrades and stairs; material reconstruction and surface protection of left reinforced concrete elements - life expectancy of the structure 15-20 years (Fig. 23).

In the proposed alternative solutions no. II, III and IV there was also defined a range of other works necessary to be implemented:

- Removal of the existing reinforced railings and mounting new steel road type balustrades.

- Design a drainage system due to the large area of rainwater collection as well as introducing an effective waterproofing system.

- Constructing a new and appropriate expansion joint system.

- Cleaning off salt, spalled plaster and concrete from the surfaces of all the elements of the driveway structure to be used in the future.

- Reparation of corrosion damage of reinforcement and concrete by proper cleaning, restoration of reinforcement and placing reprofiling layers providing proper cover of rebar.

- Applying a new cover layer on all the surfaces by spraying on the mesh or protecting the surfaces of all concrete elements with concrete repair system materials resistant to the seaside environmental influences.

\section{Final remarks}

The main scope of the conducted technical state assessment and structural analysis of the driveway was development of possible concepts of its rehabilitation.

To reach the aims of the conducted research project analyses of original design as well as of later studies on technical condition of the driveway through its exploitation life were performed. Furthermore, material investigation, structural inventory and structural modelling and calculations were made. Conclusions regarding current technical state of the driveway, identification of the reasons of their occurrence and the possibility of using the driveway until the repairs were defined.

Finally, four rehabilitation concepts were presented with emphasis on the relationship between the possible period of extending the service life of the driveway and the range of rehabilitation.

\section{References}

1. M. Fischer, Steineisendecken im Deutschen Reich 1892-1925. Dissertation. Brandenburgische Technische Universität Cottbus (2008) (in German)

2. Technical project. Driveway to the main building. Architectural design. Design Office of Maritime Construction, Gdańsk (1973)

3. Technical project. A platform and a driveway to the main building. Structural design. Design Office of Maritime Construction, Gdańsk (1973)
4. E. Grzes, Technical expertise regarding the quality of concrete in the construction of the driveway at the building M.I.R. in Gdynia (2005)

5. P. Berkowski, M. Kosior-Kazberuk, Proceedia Engineering, 172 (2017)

6. P. Berkowski, G. Dmochowski, M. KosiorKazberuk, Proceedia Engineering, 57 (2013)

7. Ł. Dorbiec, R. Jasiński, A. Piekarczyk, Diagnostics of Reinforced Concrete Structures. Methodology, field tests, laboratory tests of concrete and steel (PWN, Warsaw, 2010) (in Polish)

8. A. Zybura, M. Jaśniok, T. Jaśniok, Diagnostics of Reinforced Concrete Structures. Tests of reinforcement corrosion and protective properties of concrete (PWN, Warsaw, 2011) (in Polish)

9. M. Raupach, T. Büttner, Concrete Repair to EN 1504. Diagnosis, Design, Principles and Practice (CRC Press, Boca Raton, 2014)

10. A.P. Johnson, G.J. Klein, J.S. Lawler, SEI, vol. 29 (2019). 